\title{
Editorial Farewell
}

Behavioural Neurology is about to enter its seventh year and since its first issue in the Spring of 1988 it has gone from strength to strength. In the first three years I depended heavily on close colleagues and friends generously providing invited articles to launch it successfully. Amongst those who were instrumental in nourishing its early growth was Professor Harvey Sagar, my successor as Editor. Harvey will undoubtedly bring with him his own views as to the type of paper which the journal should encourage and this will lead to further advance and consolidation.

My hope when the journal was conceived was that it would provide a forum for interaction between neurologists interested in disorders of the cerebral cortex and basal ganglia and psychiatrists interested in biological and organic psychiatry. This has been achieved as can be seen from the mix of papers over the years. I also felt that Europe needed a specialist journal in this area to encourage interest in what is already a flourishing sub-speciality on the North American continent. This aim too has been achieved to a degree with the submission of a good sprinkling of high-quality papers from Europe. However, Behavioural Neurology has become a truly international journal, with many papers coming from distinguished Japanese colleagues and some from India, Latin America, and the Soviet Union. Despite stiff competition from comparable North American journals I have also received many papers from the United States and Canada.

I have greatly enjoyed my time as Editor of Behavioural Neurology. It is always exciting to start a new venture and see it flourish. I have been helped by my distinguished editorial board, many of whom have worked hard without any palpable reward and I take this opportunity to thank them. I also wish to express my thanks to Roger Farrand for encouraging the journal in the first place and to Rapid Communications of Oxford for taking over the reins and vastly improving the format and production of the journal since 1992. Finally I wish to thank all those who have submitted papers to what is still regarded as a new journal. All could not be published because of lack of space but all were received with gratitude and I hope the disappointed will not be discouraged from submitting and subscribing to the journal in the future.

A.J.Lees

Editor

\section{Change in Editor's Address}

Professor Harvey Sagar will commence as Editor of Behavioural Neurology from the start of Volume 7. With immediate effect, please submit all manuscripts and forward all correspondence to the Editor at the address detailed below:

\section{Professor H J Sagar}

Department of Clinical Neurology

The Royal Hallamshire Hospital

Glossop Road

Sheffield S10 2JF

UK

Tel: (+44) 742700766

Fax: (+44) 742760095 


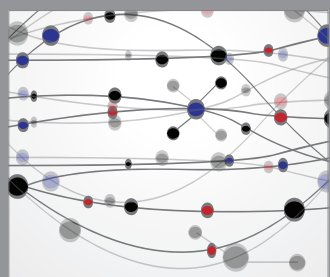

The Scientific World Journal
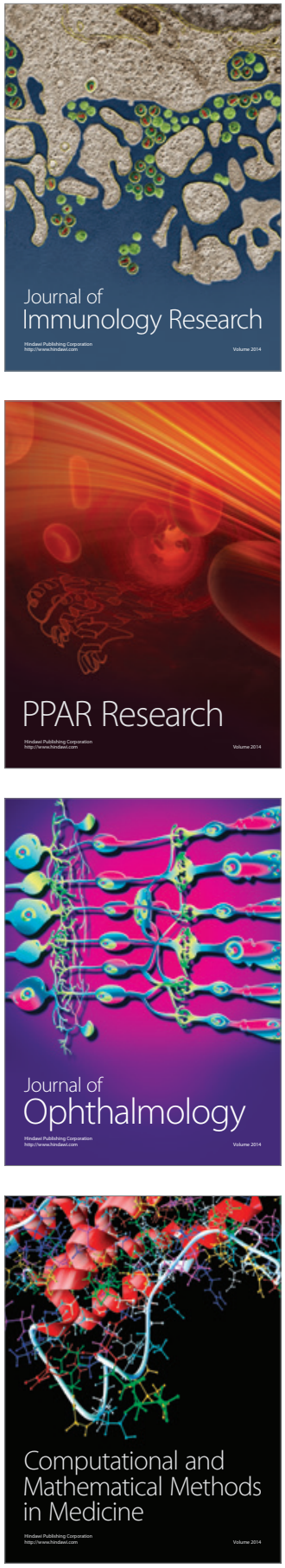

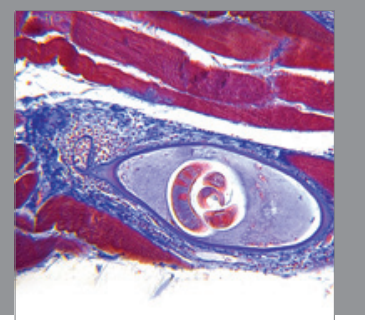

Gastroenterology

Research and Practice
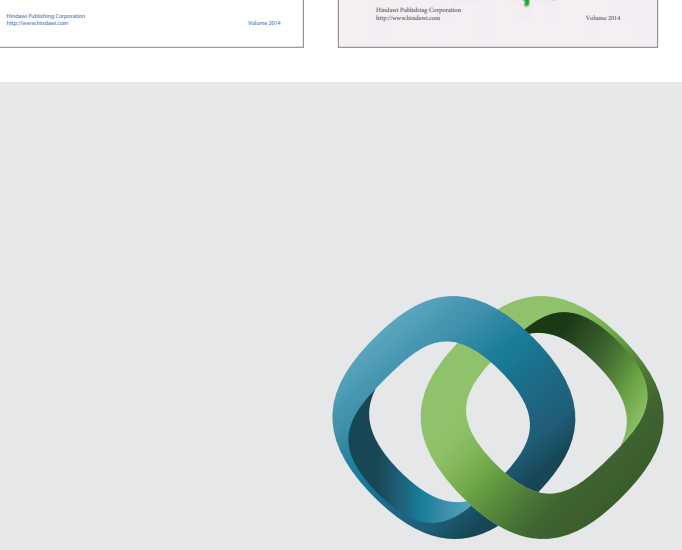

\section{Hindawi}

Submit your manuscripts at

http://www.hindawi.com
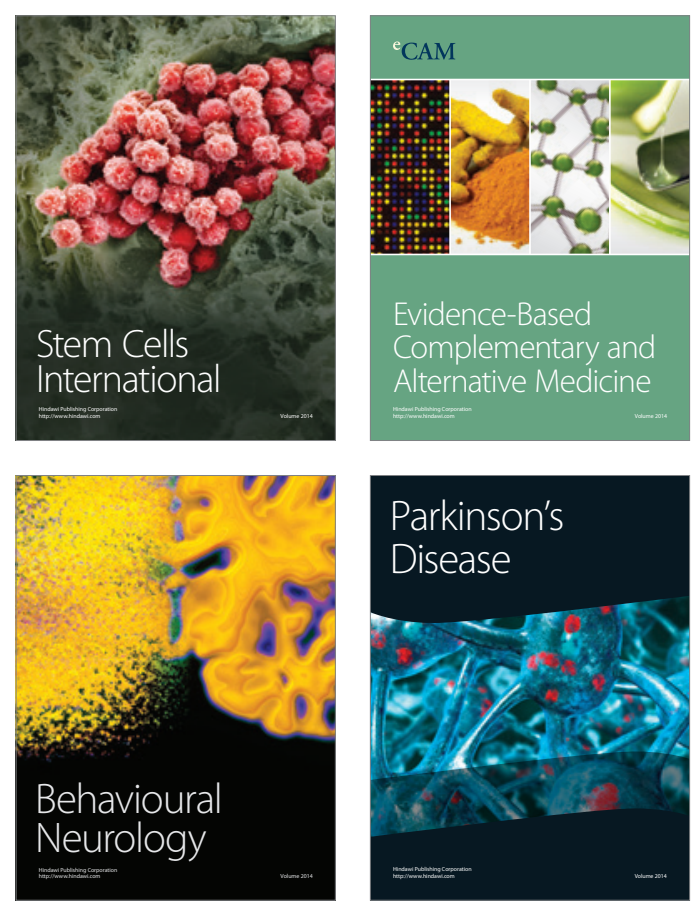

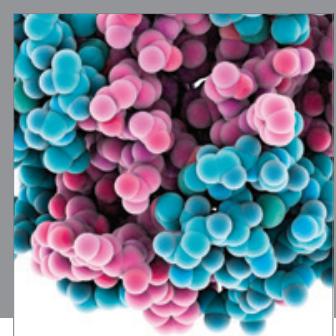

Journal of
Diabetes Research

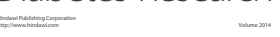

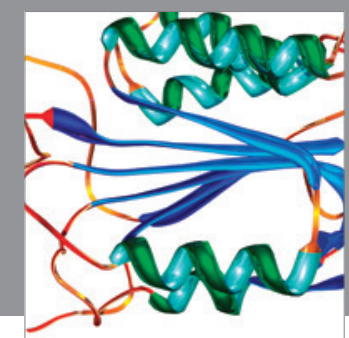

Disease Markers
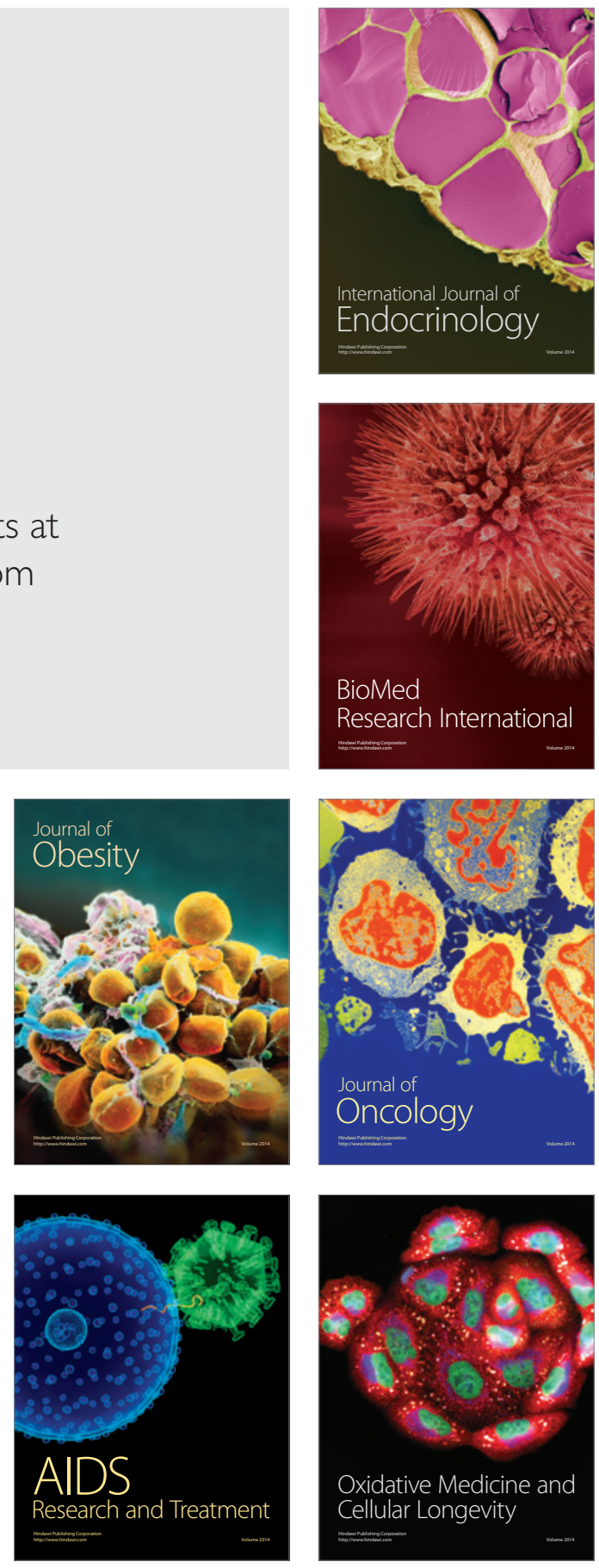